\title{
UN NUEVO GIRO HERMENÉUTICO DE LA CORTE SUPREMA EN LA APLICACIÓN DEL RECURSO DE AMPARO ECONÓMICO
}

["A New Hermeneutic Turn of the Supreme Court Regarding the Application of the Economic Protection Recourse"]

\author{
Jaime Bassa Mercado* \\ Universidad de Valparaíso, Chile \\ Christian Viera Álvarez** \\ Universidad Viña del Mar, Chile
}

\section{RESUMEN}

La Corte Suprema ha dado un giro en la interpretación del recurso de amparo económico, marcando una nueva etapa en su aplicación jurisdiccional, por cuanto lo limita al inciso $2^{\circ}$ del artículo $19 \mathrm{~N}^{\circ}$ 21 C.Pol. En este trabajo se presentan las etapas históricas de la jurisprudencia sobre la materia, las principales críticas que ha formulado la doctrina a este giro

\begin{abstract}
The Supreme Court changed the interpretation for the economic protection action, setting a new stage in its application, now restricted to the second paragraph of the article $19 \mathrm{~N}^{\circ} 21$ of the Chilean Constitution. The paper presents the historic stages of the jurisprudence, the main critiques that doctrine has formulated to this last one and the author's
\end{abstract}

* Doctor en Derecho por la Universidad de Barcelona, España; magíster en Derecho con mención en Derecho Público, por la Universidad de Chile; licenciado en Derecho por la Universidad Católica de Chile. Profesor de Derecho Constitucional de la Escuela de Derecho de la Universidad de Valparaíso, Chile. Dirección postal: Av. Errázuriz 2120, Valparaíso, Chile. Correo electrónico: jaime.bassa@uv.cl, jbassa@ gmail.com. Artículo preparado en el marco del proyecto FonDECYT No 11110290 , del cual este autor es investigador principal.

** Doctor en Derecho por la Universidad de Deusto, España; magíster en Estudios Filosóficos, por la Universidad Alberto Hurtado; licenciado en Ciencias Jurídicas por la Pontificia Universidad Católica de Valparaíso. Profesor de Derecho Constitucional en la Universidad Viña del Mar, Viña del Mar, Chile. Dirección postal: Diego Portales 90, Viña del Mar, Chile. Correo electrónico: christian.viera@opendeusto.es 
jurisprudencial y los comentarios de los autores en torno a la nueva jurisprudencia y a sus críticos.

\section{Palabras Clave}

Recurso de amparo económico - Libertad de empresa - Interpretación constitucional - Constitución económica. view on the new jurisprudential decision and its critics.

KEYWORDS

Economic protection action - Freedom of enterprise - Constitutional interpretation - Economic Constitution.

Recibido el 24 de enero y ACEPTAdo el 22 de abril de 2012.

\section{INTRODUCCIÓN}

El presente trabajo encuentra su motivación en el giro hermenéutico de la Corte Suprema, relativo al objeto de cautela del recurso de amparo económico (en adelante rae.) ${ }^{1}$, inaugurado en 2009. El artículo 19 No 21 C.Pol., garantizado por la Ley $\mathrm{N}^{\circ}$ 18.971, que establece el rae., constituye uno de los pilares fundamentales del diseño institucional que se inaugura con la promulgación del texto original de la Constitución vigente, en 1980. Su importancia llevó a crear mecanismos especiales y complementarios para la protección tanto de la libertad de empresa en tanto derecho fundamental como para la garantía del estatuto del Estado empresario, a través de mecanismos jurisdiccionales como la acción de protección ${ }^{2}$ y el propio rae e $^{3}$.

\footnotetext{
${ }^{1}$ El recurso de amparo económico es una acción legal que persigue impetrar la actuación del órgano para que ejerza jurisdicción y solucione el conflicto sometido a su conocimiento. No se trata de un recurso procesal propiamente tal, ya que los recursos son los medios que concede la ley a la parte que se cree perjudicada por una resolución judicial para obtener que ella sea modificada o dejada sin efecto. Sobre el punto, véase: ZúNiga Urbina, Francisco, El recurso de amparo económico: doctrina jurisprudencial, en La Revista de Derecho 2 (2001), p. 265.

${ }^{2}$ Sobre el punto, véase: GuZmán SuÁrez, Lionel, Paralelo entre el recurso de protección y el recurso de amparo económico, en Gaceta Jurídica, 182 (1999), pp. 49-67. Puede verse también la sentencia de la Corte Suprema, de 3 de septiembre de 1998, rol 935-98 Recurso de amparo económico Aguas Cordillera S.A contra Ministro de Obras Públicas”, en Gaceta Jurídica, 219, pp. 48-58, considerandos $4^{\circ}$ y $5^{\circ}$, p. 57.

${ }^{3}$ Entre muchos, véanse: Dougnac RodríGuez, Fernando, La garantía constitucional del $N^{\circ} 21$ del articulo 19 de la Constitución en relación con las demás que configuran el orden público económico, en Gaceta Jurídica, 68 (1986), pp. 6-12; Soтo KLoss, Eduardo, La actividad económica en la Constitución Politica de la República de Chile (La primacía de la persona humana), en Ius Publicum, 2 (1999), p. 121; Bertelsen Repetto, Raúl, El Estado empresario en la Constitución de 1980, en Revista Chilena de Derecho, 14 (1987) No 1, pp. 120-121; FARÍAs KAnACRI, Alejandro, El derecho a
} 


\section{LA “CONSTituCión ECONÓMiCA” vigente EN Chile.}

A pesar de la reforma del año 2005, en el plano económico social persisten los paradigmas impuestos en la Carta de 1980, ya que aún se encuentran los componentes ideológicos de ese tiempo, originariamente autoritarios, neoliberales y iusnaturalistas, que apuntan a una refundación del capitalismo. Como señala Zúñiga: "el Constituyente originario proyecta una herencia perdurable en lo económico-social, bajo un signo ideológico neoliberal, que es una "constitución económica" y una Constitución Social centradas en ciertos componentes torales [...] [uno de los cuales es] el concepto restringido de Estado empresario del artículo 19 No 21 "4.

Asimismo, la Constitución, si bien no explícitamente, consagra la economía de mercado como el sistema económico imperante, especialmente por la protección de la libertad de empresa, la estructura del derecho de propiedad, el rol del Estado en la economía y los principios de políticas monetaristas ${ }^{5}$.

desarrollar actividades económicas y su regulación, en Persona y Sociedad, 4 (2000) 3, pp. 157-158; Navarro Beltrán, Enrique, El Estado empresario a la luz de la Constitución de 1980, en Revista de Derecho Público, 62 (2000), pp. 33-37; Fermandois, Arturo, Derecho constitucional económico (2 ${ }^{\mathrm{a}}$ edición, Santiago, Ediciones Universidad Católica de Chile, 2006), I, pp. 59-60; Larroulet Vignau, Cristián, Visión económica de la Constitución de 1980, en Revista de Derecho Público, 62 (2000), p. 95.

${ }^{4}$ Zúñiga Urbina, Francisco, Vieja-Nueva Constitución, en Estudios Constitucionales, 5 (2007) 1, p. 357. Otros elementos importantes que señala Zúñiga son: "el reconocimiento y tutela extraordinaria de los derechos fundamentales de libertad civil en especial de alcance patrimonial y económico; débil reconocimiento de los derechos económicos y sociales; reconocimiento amplio de la autonomía técnica y patrimonial del Banco Central como organismo enderezado a la protección de cierto orden económico y modelo de desarrollo, y consagración de una regla de delimitación de lo públicoprivado como es el principio de subsidiariedad, que a pesar de ser un principio plurisignificativo, se impone con fuerza su acepción negativa o pasiva que retrae al Estado a funciones en la economía y sociedad civil mínimas" (ZÚÑIGA, Francisco, cit. [n. 4], p. 357). En el mismo sentido, véase: Vergara, Pilar, Auge y caída del neoliberalismo en Chile (Santiago, Flacso, 1985), pp. 270-271, Ferrada Bórquez, Juan Carlos, La Constitución de 1980. Algunas reflexiones criticas, en Revista de Derecho Universidad Austral de Chile, 11 (2000), p. 52; Guerrero BeCar, José Luis, La libertad para desarrollar actividades económicas del artículo $19 N^{\circ} 21$ y la Constitución Económica, en Persona y Sociedad, 4 (2000) 3, pp. 154-155.

${ }^{5}$ Sobre el monetarismo, aunque no compartimos la interpretación originalista de la Constitución, es posible afirmar que sus redactores postulaban una propuesta monetarista. Al respecto baste ver la discusión relativa al endeudamiento por parte del Estado en Actas Oficiales de la Comisión Constituyente, sesión 393ª de 4 de julio de 1978 pp. 3010-3018; o el rol del Banco Central, ibíd., sesión 403a , de 18 de julio de 1978, pp. 3235-3246). Conviene recordar que desde la perspectiva de los postulados económicos, para este enfoque, la inflación es el principal inconveniente para lograr 
La dificultad que se genera en este punto no es por el reconocimiento de la economía de mercado (muchas Constituciones contemporáneas asílo hacen), sino por la interpretación que se ha hecho de ella y que ha legitimado la mercantilización de las principales y más importantes esferas de la realidad, lo que incluye la salud, educación y seguridad social. Incluso, podríamos afirmar que se trata de una interpretación incompatible con las bases fundamentales de la democracia constitucional, dada la alteración que produce en la protección de los derechos e intereses de las personas.

Puede ser que en Chile la imposición de este modelo sea el resultado de una sobrerreacción a las políticas económicas que rigieron en Chile en las décadas de los sesenta y setenta, ya que se ha puesto el énfasis en que los buenos resultados económicos simplemente requieren de liberalización comercial, estabilidad económica y correcta fijación de precios, asumiendo que los mercados privados por sí solos distribuirán eficientemente los recursos, generando un fuerte y dinámico crecimiento; en esta visión queda implicada una sobrevaloración de la capacidad de autorregulación de los mercados? La situación normativa actual de la "constitución económica" chilena, pone el acento en que la función de lo colectivo y del Estado es asegurar que el interés privado se concrete en todos los individuos, creando las condiciones para que éstos se puedan desarrollar plenamente en lo material ${ }^{8}$.

desarrollo y crecimiento, generando, al mismo tiempo, efectos desfavorables sobre la distribución del ingreso por lo cual se demanda una clara preferencia por una tasa de inflación lo más cercana posible a cero. Para lograr este propósito, el monetarismo se concentra en el empleo de unos pocos instrumentos de política: control de la oferta monetaria y reducción del déficit fiscal, devaluación del tipo de cambio, liberalización de los precios y eliminación de subsidios. Estos instrumentos permitirán producir efectos distributivos neutrales, debido a la aplicación de una norma uniforme para todos los agentes económicos, lo que implica el término de toda suerte de discriminación [véase: FoXley, Alejandro, Experimentos neoliberales en América Latina, en Estudios Cieplan, 59 (1982), pp. 15-16].

${ }^{6}$ Ferrajoli, Luigi, La democracia constitucional, en Ferrajoli, Democracia y garantismo (Madrid, Trotta, 2010), pp. 25-41.

${ }^{7}$ Véanse: Estévez VALENCIA, Jaime, Visión sobre la constitución económica, en Revista de Derecho Público, 62 (2000), p. 99; Masbernat Muñoz, Patricio - HurtaDo Contreras, José Tomás, Crítica al concepto de orden público económico, en Revista de Derecho Público, 66 (2004), p. 209. No extraña, entonces, que existan autores que para explicar el actual entramado constitucional recurran a la historia económica previa para justificar la institucionalidad jurídica-económica que devino en Chile. Al respecto, véase: Cuevas Farren, Gustavo, Protección constitucional de la libertad económica. Notas y reflexiones, en Letras Jurídicas, 2 (Universidad de Guadalajara, Guadalajara, 2006), pp. 2-9. Disponible en: http://www.letrasjuridicas.cuci.udg.mx/numeros/02/ GCF2006.pdf [fecha de visita: 16 de mayo de 2012].

${ }^{8}$ Véase: Avilés HernándeZ, Víctor, Orden público económico: noción crítica, en 
Sin embargo, la "constitución económica" chilena se inserta en el modelo vigente de Constitución, caracterizada por su techo ideológico abierto, propio de un sistema democrático que se sustenta en acuerdos entre diversos que fundan sus pretensiones en diferentes cosmovisiones. Por lo mismo, éste será un espacio "en que el elemento esencial es definir el 'mínimum constitucional' de reglas y principios del sistema. Asimismo, entre la libertad económica y la intervención del Estado existe una amplia gama de políticas económicas concretas". En estas materias, se espera que la Constitución garantice los mínimos de la convivencia, permitiendo la posibilidad de concretar posteriormente tantos los aspectos de mayor detalle como aquellos que generan menores consensos en la sociedad. Así se entiende, a nuestro juicio, la garantía de libertad política que postula Hesse, en el actual Estado constitucional ${ }^{10}$.

Por tanto, la Constitución se interpreta desde la diversidad de la sociedad, considerando su techo ideológico abierto y sus normas con estructura de principio; esta interpretación se garantiza a través de la apertura del proceso deliberativo, para satisfacer de mejor manera fines en constante evolución, y no mediante el recurso a las Actas de la Comisión de Estudios de la Nueva Constitución argumento de autoridad que cierra el debate antes que garantizar la libertad política incorporada en toda Constitución. Como señalan Masbernat y Hurtado "el constante recurso a la CENC. es inadecuado para el desarrollo dogmático, en la medida que concede valor per se a las opiniones de los comisionados, sin ninguna evaluación crítica de ellas"11.

Consideramos al Estado le corresponde desarrollar ciertas actividades económicas, especialmente en función del respeto y promoción de los derechos sociales y de la superación de la pobreza, ya que, "aun cuando la economía de mercado funcione adecuadamente, nada garantiza que la distribución del ingreso resulte socialmente aceptable [...] por ello el Estado interviene para redistribuir ingresos y oportunidades, corrigiendo con ello, los efectos deseados del mercado"12. El Estado no puede desentenderse de ciertas ne-

Revista de Derecho Público, 63 (2001), p. 338.

${ }^{9}$ ZúNíiga Urbina, Francisco, Constitución económica y Estado empresario, en Revista de Derecho Público, 63 (2001), p. 343.

${ }^{10}$ Cf. Hesse, Konrad, Concepto y cualidad de la Constitución, en Hesse, Escritos de Derecho constitucional (Madrid, Centro de Estudios Constitucionales, 1983), pp. $1-31$.

${ }^{11}$ Masbernat, Patricio, cit. (n. 7), p. 212.

${ }^{12}$ Landerretche, Oscar, Notas sobre el rol del Estado en la Economía, en La Revista de Derecho, 4 (2003), p. 197. Funda su afirmación este autor, economista de profesión, en que "los mercados operan sobre la base de los recursos con que cada actor cuenta para incidir en ellos. Si la distribución es muy desigual y ella afecta significativamente las oportunidades del progreso individual, es muy probable que la desigualdad se mantenga y que sectores importantes de la población permanezcan en una condición 
cesidades sociales, hoy protegidas en la forma de derechos fundamentales sociales que, si fueran dejadas al libre arbitrio de la iniciativa privada, no llegarían nunca a satisfacerse.

La apertura de los conceptos constitucionales, unida a una lectura dinámica de la sociedad y de la Constitución, permite que la interpretación pueda responder a las circunstancias sociales, políticas o económicas en las que encuentra su legitimidad, evitando el peligro de una petrificación del Derecho, riesgo latente y del que no pocas veces pecan los sistemas. Que la realidad social va cambiando no es un descubrimiento copernicano; ahí está la historia de los derechos fundamentales para mostrar cómo la realidad social ha determinado el contenido y la estructura del ordenamiento jurídico. La dificultad estriba en una lectura adecuada de la realidad y de la necesaria adaptación del Derecho. Por ello, resulta razonable postular que el sistema jurídico debe manifestarse abierto a esta problemática y generar la flexibilización de los criterios que por tanto tiempo han acompañado el devenir de la sociedad. No es inocuo plantear un determinado modelo de interpretación constitucional sobre otro. Si bebemos de una fuente flexible, las cláusulas abiertas pueden ser determinadas evolutivamente en su contenido material, pero, si nuestra fuente es restringida, quedamos atrapados por la tradición y el momento inicial del pacto, por más razonable que sea. El argumento de autoridad de la "original intent" o la buena fe, no puede arrastrar al ordenamiento jurídico a la deslegitimación por recurrir a criterios ya superados por la realidad.

Ahora bien, el contenido que se le atribuye al orden público económico en general y al estatuto del Estado empresario en particular, no se desprende pura y simplemente del texto de la Constitución. Es decir, el contenido material de este concepto no es autoevidente, sino que se ha construido por la jurisprudencia y, especialmente, por la doctrina, a través de la interpretación. Ha sido la doctrina la que, a partir de la interpretación del texto vigente, ha afirmado que la Constitución consagra determinada institución o protege determinado modelo. Estas afirmaciones se sustentan en dos pilares fundamentales.

a) Por un lado, una interpretación originalista de la Constitución, que a través de una lectura parcial, acrítica y sin mayor discernimiento sobre las opiniones de los comisionados que efectivamente puedan poseer "voluntad constituyente", se ha buscado perpetuar determinado diseño institucional, cerrando el debate característico del proceso democrático en torno a las

socialmente inaceptable, desaprovechándose su potencial productivo y ciudadano y reduciéndose su contribución al desarrollo nacional" (LANDERRETCHe Oscar, cit. n. 12, p. 155). 
instituciones de dicho diseño. Así, se ha hecho explícita la concepción de la Constitución que se esconde tras esta teoría de la interpretación constitucional: una Carta testamento, cerrada e inmodificable, que se protege a través del argumento de autoridad de una interpretación originalista.

b) Por otro lado, la interpretación constitucional que realiza la doctrina se sustenta, por cierto, en la normativa constitucional. En efecto, para dotar de contenido material a ciertas normas y construir estas instituciones, se ha recurrido a las propias normas constitucionales. Pero no a todas las normas ni a cualquiera, sino a aquellas seleccionadas. Por ejemplo: el contenido material del estatuto del Estado empresario, se ha construido a partir de una interpretación selectiva de la Constitución, donde se ha privilegiado cierta lectura del principio de subsidiariedad en desmedro de otras normas constitucionales, por ejemplo, la igualdad de oportunidades (artículo $1^{\circ}$ inciso $5^{\circ}$ ) o el principio de solidaridad (artículo $3^{\circ}$ ). Ciertamente, todas estas normas tienen legitimidad suficiente para contribuir en el ejercicio hermenéutico que supone dotar de contenido material a normas abiertas e indeterminadas. Pero ello hace evidente que se trata de un contenido que se construye a partir de una serie de decisiones (políticas, metodológicas, hermenéuticas), pero que ni es autoevidente ni se desprende de la Constitución en términos necesarios. Se trata, en definitiva, sólo de una interpretación posible de la Carta, de entre varias ${ }^{13}$.

Por ello, resulta fundamental revisar los criterios hermenéuticos utilizados por los tribunales, ya que estos son determinantes en la configuración de la Constitución económica.

\section{ETAPAS EN LA HERMENÉUTICA}

\section{DEL RECURSO DE AMPARO ECONÓMICO Y EN SU APLICACIÓN}

La jurisprudencia ha concebido de diversas formas el objeto de protección del rae.; ello da cuenta de la ausencia de un contenido constitucional fijo en materia de derechos fundamentales y de la importancia de la interpretación constitucional en la configuración del ordenamiento jurídico chileno. Así, la aplicación del rae. muestra tres etapas en la jurisprudencia.

a) En un primer momento, las Cortes han entendido que esta acción sólo resguarda el cumplimiento del inciso $2^{\circ}$ del artículo $19 \mathrm{~N}^{\circ} 21$ C.Pol., es decir, es un mecanismo de cautela ante los eventuales desbordes del Estado empresario. Esta primera etapa, que se verifica principalmente en la década

${ }^{13}$ Sobre la neutralidad, véase: BAssa MERCADO, Jaime, Neutralidad politica y enseñanza del Derecho constitucional en Chile, en HenríQuez, Miriam (coord.), Perspectiva del Derecho Constitucional desde el mirador del Bicentenario (Santiago, Asociación Chilena de Derecho Constitucional, 2011), pp. 271-289. 
de 1990, ha recibido el nombre de tesis histórica, por cuanto se fundamenta en el origen histórico del proyecto de ley que contemplaba la acción ${ }^{14}$. Se le llama etapa inicial de interpretación restringida, por cuanto la interpretación restringió la tutela del rae. al inciso $2^{\circ}$ del artículo $19 \mathrm{~N}^{\circ} 21$ C.Pol..$^{15}$. Durante los primeros cinco años de vigencia del rae., ésta fue la interpretación que postularon los Tribunales chilenos ${ }^{16}$.

b) La segunda etapa, que marca un giro en la jurisprudencia, extiende la aplicación del rae. a ambos incisos del artículo $19 \mathrm{~N}^{\circ} 21 \mathrm{C}$.Pol. Esta es la llamada tesis literalista ${ }^{17} \mathrm{o}$ etapa intermedia de interpretación amplia ${ }^{18} ; \mathrm{y}$ es la tendencia que siguió la jurisprudencia hasta el año 2009, que básicamente sostiene que "del tenor literal claramente manifestado en el texto de la ley 18.971, aparece que el recurso ampara la garantia constitucional estableciendo acción popular para denunciar todas las infracciones a dicha norma constitucional completa, ya que no hace distinciones entre sus dos incisos" 19 . Específicamente, "que la ley 18.971 estableció el recurso especial de amparo, para denunciar las infracciones al artículo 19, número 21 C.Pol., sin hacer

${ }^{14}$ Véase: Navarro Beltrán, Enrique, El recurso de amparo económico y su práctica jurisprudencial, en Estudios Constitucionales, 5 (2007) 2, p. 104.

${ }^{15}$ Véase: Hernández Emparanza, Domingo, El recurso de amparo económico: una tendencia jurisprudencial peligrosamente reduccionista, en Estudios Constitucionales, 8 (2010) 1, pp. 444-445.

${ }^{16}$ Sentencia de la Corte de Apelaciones de Santiago, de 17 de abril de 1991, rol No 785-91, recaída en recurso de amparo económico caratulado: "Enrique Llano Macuer contra Secretario Regional Ministerial de la Región Metropolitana de Transportes y Comunicaciones", en Gaceta Jurídica, 130, considerando 6, p. 42; "Un caso como el que habría afectado al requirente debe ser reclamado por medio del recurso establecido en el artículo 20 de la Constitución y no por el de la ley 18.971; este último debe entenderse creado para proteger otras situaciones cubiertas por el artículo $21 \mathrm{~N}^{\circ} 19$ del texto constitucional, como es la que se contempla en su inciso segundo"; sentencia de la Corte de Apelaciones de Santiago, de 6 de mayo de 1992, recaída en recurso de amparo económico caratulado “Asociación Gremial Armadores Artesanales VIII Región y otro contra Presidente de la República”, rol No 738-92, en Gaceta Jurídica, 143, considerando $9^{\circ}$, p. 65: "este recurso especial está relacionado con el derecho del Estado y sus organismos para desarrollar actividades empresariales o participar en ellas, en otras palabras, se refiere a lo establecido en el inciso segundo del artículo 21. Por consiguiente, no se relaciona con el inciso primero del referido artículo que protege el derecho a desarrollar cualquier actividad económica, que de conformidad a lo establecido en el artículo 20 de la Carta Fundamental, está resguardado por el recurso de protección”.

${ }^{17}$ Navarro, Enrique, cit. (n. 14), p. 105.

${ }^{18}$ Hernández, Domingo, cit. (n. 15), p. 445.

${ }^{19}$ Sentencia de la Corte de Apelaciones de Santiago, de 26 de enero de 1995, recaída en el recurso de amparo económico caratulado "Agropecuaria Menichetti S.A.I. contra Banco del Estado de Chile", rol No 3899-94, en Gaceta Jurídica, 177, considerando $5^{\circ}$, p. 22. 
distinción alguna entre las diversas situaciones planteadas en ambos incisos del señalado número $21^{\prime 20}$.

c) La tercera etapa es inaugurada por la Corte Suprema en el caso "González Illanes con Municipalidad de Santiago" ${ }^{21}$. En esta sentencia, la Corte ha señalado que si bien el artículo único de la Ley $\mathrm{N}^{\circ} 18.971$ “denota claridad en su tenor literal, no ocurre lo mismo con su sentido, que resulta ambiguo en cuanto a la finalidad que tuvo en vista el legislador"22. Por lo anterior, y para dar una interpretación correcta a la materia, es necesario acudir a otros principios de interpretación que complementan el elemento gramatical, como son el lógico-histórico y el sistemático ${ }^{23}$.

La sentencia señala que, desde la perspectiva histórica: "el legislador instituyó un mecanismo de tutela jurisdiccional destinado a amparar a los particulares en su derecho a la libertad económica cuando ella resulte afectada por la actividad del Estado llevada a efecto con infracción a las regulaciones que sobre la materia se establecen en el articulo $19 \mathrm{~N}^{\circ} 21$ inciso $2^{\circ} \mathrm{C}$. Pol. Política; determinación que, de seguro, obedeció al convencimiento de quienespropiciaron el establecimiento de dicho cuerpo normativo en orden a que el recurso de protección contemplado en el artículo 20 de la misma Carta carecía de la aptitud

${ }^{20} \mathrm{Y}$ continúa el fallo: “[...] las argumentaciones vertidas por la recurrida para concluir que el amparo económico sólo es procedente cuando se ha producido una infracción al inciso segundo del artículo 19 número 21 de la Carta Fundamental, no llevan al convencimiento de esta Corte en cuanto que asi deba resolverlo, variando por lo demás con ello la jurisprudencia establecida por esta Sala especializada" (sentencia de la Corte Suprema, de 10 de enero de 1996, recaída en el recurso de amparo económico caratulado "Endesa contra Dirección General de Aguas", rol No 33.502, en Gaceta Jurídica, 187, Vistos, párrafos 2-3, p. 49). En igual sentido, véase la sentencia de la Corte de Apelaciones de San Miguel, de 17 de diciembre de 1997, recaída en recurso de amparo económico caratulado "Empresa Metropolitana de Tratamiento y Disposición de Basuras Limitada contra Alcalde de la Municipalidad de San Bernardo", rol No 186-97, en Gaceta Jurídica, 211, considerando $2^{\circ}$, p. 35; sentencia de la Corte Suprema, de 28 de marzo de 2000, recaída en recurso de amparo económico caratulado "Domingo Eduardo Escobar González contra Alcalde de la Ilustre Municipalidad de Recoleta”, rol No 835-00, en Gaceta Jurídica, 237, considerando 3º p. 26; sentencia de la Corte de Apelaciones de Valparaíso, de 19 de diciembre de 2000, recaída en recurso de amparo económico caratulado "Alimar contra Subsecretaría de Pesca", rol No 558-00, en Gaceta Jurídica, 247, considerando $9^{\circ}$, p. 40.

${ }^{21}$ Sentencia de la Corte Suprema, de 9 de diciembre de 2008, recaída en recurso de amparo económico Sergio Luis González Illanes contra I. Municipalidad de Santiago, rol No 501-09, en base Legal Publishing, $\mathrm{N}^{\circ} 41887$.

${ }^{22}$ Sentencia de la Corte Suprema, rol No 501-09, considerando $5^{\circ}$.

${ }^{23}$ Sentencia de la Corte Suprema, rol No 501-09, considerando $6^{\circ}$. 
requerida para constituir un resguardo con la eficacia suficiente respecto de la intangibilidad que debe ostentar dicha garantía esencial"24.

Desde la perspectiva sistemática, también se puede llegar a la misma conclusión. Mientras el recurso de protección establece una acción a favor de quien, como consecuencia de acciones u omisiones ilegales o arbitrarias de terceros, sufra privación, perturbación o amenaza en el legítimo ejercicio de determinados derechos, en el rae., cualquier persona puede denunciar las infracciones al artículo $19 \mathrm{~N}^{\circ} 21$, sin que el actor necesite tener interés actual en los hechos a que se refiere la denuncia. Crea así la ley una acción popular, que refleja el deseo del legislador en orden a amparar el derecho a la libertad económica cuando tales vulneraciones provengan de la actividad empresarial del Estado quebrantando las normas de orden público económico ${ }^{25}$.

Continúa la sentencia dando razones para considerar que el rae. no es el medio idóneo para cautelar el inciso $1^{\circ}$ del artículo 19 No 21 : "existen fundadas razones que conducen a descartar el amparo económico como instrumento idóneo para dispensar protección al derecho a desarrollar una actividad económica lícita contemplado en el artículo $19 N^{\circ} 21$ inciso $1^{\circ}$ de la Carta Fundamental. La primera estriba en la imposibilidad de estimar como criterio racional que una persona directamente afectada por la vulneración de dicha garantia de treinta dias para deducir el recurso de protección, en tanto que un tercero sin interés actual alguno en la materia cuente para ello con un plazo de seis meses. Enseguida, el diseño con que el referido cuerpo legal reguló el amparo económico impide considerarlo como un remedio eficaz disponible a favor de un particular para la salvaguarda de la garantia en referencia, desde que no se entregó al órgano jurisdiccional la facultad de adoptar providencias cautelares prontas e inmediatas para brindar resguardo al afectado, como si se establecen tratándose del recurso de protección" ${ }^{\text {26 }}$. Asimismo: "[esas] razones resultan aptas para producir en estos sentenciadores el suficiente grado de convencimiento en orden a la inidoniedad del recurso de amparo económico para salvaguardar la garantía fundamental reconocida en el articulo $19 N^{\circ} 21$ inciso $1^{\circ}$ de la Carta Fundamental"27.

\footnotetext{
${ }^{24}$ Sentencia de la Corte Suprema, rol No 501-09, considerando $10^{\circ}$.

${ }^{25}$ Sentencia de la Corte Suprema, rol No 501-09, considerando $11^{\circ}$.

${ }^{26}$ Sentencia de la Corte Suprema, rol No 501-09, considerando $12^{\circ}$.

${ }^{27}$ Sentencia de la Corte Suprema, rol No 501-09, considerando $13^{\circ}$. Esta sentencia da inicio a la nueva jurisprudencia, y el criterio sentado en ella ha sido confirmado posteriormente. Al respecto, véanse: sentencia de la Corte Suprema, de 16 de abril de 2009, recurso de amparo económico "Sociedad Celcon S.A. contra Instituto Nacional de Normalización”, rol No 1.188-2009, LegalPublishing No 41952; sentencia de la Corte Suprema, de 22 de abril de 2009, recurso de amparo económico "Jorge Iván Monje Fernández y otros contra Banco Santander Chile”, rol No 650-09, LegalPublishing No 42000; sentencia de la Corte Suprema, de 27 de abril de 2009, recur-
} 
Es decir, la nueva jurisprudencia se asienta, principalmente, en dos elementos: la distinción entre interés público e interés privado comprometidos en cada inciso, y la posibilidad de adoptar medidas cautelares inmediatas para proteger el interés vulnerado.

\section{La nueva jurisprudencia de la Corte Suprema. PRINCIPALES OBJECIONES Y COMENTARIOS CRÍTICOS}

Esta nueva línea jurisprudencial, inaugurada con el fallo de la Corte $\mathrm{Su}-$ prema rol 501-09, ha generado reacciones críticas por parte de la doctrina. Estas críticas apuntan a dos elementos centrales: $i$ ) el tenor de la Ley $\mathrm{N}^{\circ}$ 18.971 es claro y, por lo tanto, no se debe desatender; y ii) la intención del legislador en orden a proteger sólo el inciso $2^{\circ}$ del artículo 19 № 21 C.Pol., no es evidente. Así, las críticas concluyen que la Corte vulneraría los criterios de interpretación constitucional que se fundan en los derechos fundamentales, principalmente el principio pro bomine $e^{28}$.

La primera objeción que se plantea a la nueva jurisprudencia, se argumenta desde la literalidad de la ley. A este respecto, Hernández es categórico

so de amparo económico "Danilo Mauricio Méndez Méndez y otros contra Ilustre Municipalidad de Coquimbo”, rol No 1.709-09, LegalPublishing No 41953; sentencia de la Corte Suprema, de 7 de mayo de 2009, recurso de amparo económico "Agrícola Magalys Werner Leischner E.I.R.L. contra Juez del Segundo Juzgado de Letras de Osorno y Banco Santander Chile”, rol No 1.655-09, LegalPublishing No 41993; sentencia de la Corte Suprema, de 27 de mayo de 2009, recurso de amparo económico “Alex Fabián Alarcón Peña contra I. Municipalidad de Antuco", rol No 2.537-09, LegalPublishing No 42091; sentencia de la Corte Suprema, de 6 de agosto de 2009, recurso de amparo económico "Beatriz del Carmen Barrios Verdugo contra Sociedad Supermercados Korlaet Ltda.”, rol No 5971-2009, LegalPublishing No 42615; sentencia de la Corte Suprema, de 10 de septiembre de 2009, recurso de amparo económico "Hotelera Rent a Home Limitada contra Municipalidad de Providencia", rol No 6.959-09, LegalPublishing No 43086; sentencia de la Corte Suprema, de 28 de diciembre de 2009, recurso de amparo económico "Quercia Onofri Rizieri Lorenzo y otro contra Municipalidad de Nuuñoa”, rol No 9.458-09, LegalPublishing No 43099; sentencia de la Corte Suprema, de 8 de junio de 2010, recurso de amparo económico "Víctor Eduardo Zapata Avilés contra Alcalde de la Comuna de Yungay y otro", rol No 3.573-10, LegalPublishing No 44886.

${ }^{28}$ Véase Hernández (2010) 447-456; Nogueira Alcalá, Humberto, Análisis critico sobre línea jurisprudencial de la Sala Constitucional de la Excma. Corte Suprema de Justicia sobre el recurso de amparo económico, en Gaceta Jurídica, 360 (2010), pp. 7-27. También se puede ver una profundización del artículo de Nogueira en NogUEIra Alcalá, Humberto, Análisis critico sobre linea jurisprudencial de la Sala Constitucional de la Excma. Corte Suprema de Justicia sobre el recurso de amparo económico, en Ius et Praxis, 16 (2010) 2, pp. 415-442. 
para afirmar que la Ley $\mathrm{N}^{\circ} 18.971$ no distingue "entre los dos párrafos que comprende el precepto constitucional [artículo $19 \mathrm{~N}^{\circ} 21$ ]. Luego, "ubi lex non distinguit nec non distinguere debemus" ${ }^{29}$. Por su parte, Nogueira señala que "no es correcto por los operadores jurisdiccionales recurrir a la intención del legislador cuando la norma legal en su tenor gramatical es claro, aun si recurriéramos a la interpretación privatista del Código Civil, cosa que sería inadecuado ya que estamos en el ámbito del derecho procesal constitucional, el Código Civil sólo posibilita recurrir a la intención o espíritu del legislador 'para interpretar una expresión obscura de la ley', lo cual no es el caso de la disposición analizada, donde la Sala Constitucional en su posición de mayoría reconoce en el fallo en análisis que la disposición es literalmente 'clara' en el considerando tercero de la sentencia analizada" ${ }^{30}$.

La segunda objeción se plantea desde la historia fidedigna del establecimiento de la norma. En opinión de Hernández, la ley es inequívoca en torno a proteger mediante el rae. no sólo la actividad del Estado empresario, sino también la libertad de emprendimiento; para justificar dicha afirmación, el autor recurre a fuentes documentales que forman parte de la historia de la norma. Señala que es "ilustrativo, en esta perspectiva, el acta con que la Junta de Gobierno aprobó los dos proyectos, donde, refiriéndose en particular al recurso plasmado en la primera, se señala simplemente: 'su texto contempla la creación de un recurso especial para garantizar los derechos de los particulares frente a las infracciones que pudieran cometerse a la norma del $\mathrm{N}^{\circ}$ 21 del artículo 19 C.Pol."'31.

Sin embargo, nos parece que se trata de una propuesta forzada, porque omite el "Informe técnico de los ministros", que es el documento más contundente para explicar la razonabilidad del rae. y que forma parte de la historia del establecimiento de la norma. Así, pareciera forzar la opinión de la Junta Militar a favor de una interpretación literal, al señalar que "si bien algunos informes y oficios, durante la discusión en el seno de los órganos del sistema legislativo diseñado en el gobierno militar, se orientan a subrayar la importancia de la acción jurisdiccional que se crea, para la defensa de los particulares frente a los excesos del Estado-empresario, es lo cierto que no hay antecedentes que permitan afirmar que el propósito del legislador haya sido excluir de su ámbito de cobertura los ilícitos cometidos por particulares en el desarrollo de sus actividades económicas" 32 .

${ }^{29}$ Hernández, Domingo, cit. (n. 15), p. 448.

${ }^{30}$ Nogueira, Humberto, cit. (n. 28), p. 16.

${ }^{31}$ Hernández, Domingo, cit. (n. 15), pp. 448-449.

${ }^{32}$ Hernández, Domingo, cit. (n. 15), p. 448. Sin embargo, es evidente, que el "Informe técnico de los ministros del Interior, Economía y Hacienda" sí establece que esta acción va dirigida a la protección de los excesos del Estado empresario. 
Con todo, el argumento de mayor peso que sostienen ambos autores afirma que: $i$ ) esta nueva propuesta hermenéutica constituye una regresión en la protección de los derechos fundamentales; y ii) yerra la Corte Suprema al aplicar a materias constitucionales los criterios de interpretación establecidos en el Código Civil, más propios del Derecho privado. Ambos autores recurren a las reglas de interpretación propias del Derecho constitucional, entre las que destaca el principio favor personae o pro homine ${ }^{33}$, y a la normativa internacional en materia de derechos humanos.

$\mathrm{Al}$ respecto, creemos que es importante revisar críticamente tanto la nueva línea jurisprudencial como las críticas que se le han formulado por la doctrina.

\section{Las reglas tradicionales de interpretación de la ley.}

Si bien las reglas de interpretación del Código Civil pueden ser útiles, no son suficientes cuando se trata de materias relacionadas con el Derecho constitucional y, principalmente, de los derechos fundamentales, porque para el sistema de derechos fundamentales es necesario considerar otros criterios de interpretación que no se encuentran en las normas hermenéuticas del Derecho privado ${ }^{34}$.

Los criterios de interpretación que confluyen en la escuela histórica de Savigny ${ }^{35}$ y generalmente contenidas en los códigos civiles ${ }^{36}$, son uno de los

${ }^{33}$ Hernández, Domingo, cit. (n. 15), pp. 455-456; Nogueira, Humberto, cit. (n. 28), pp. 15-16. Este último incluso señala que: "tal trasgresión explicitada en los fallos anteriores por la Corte Interamericana de Derechos Humanos se concreta por la Sala Constitucional de la Corte Suprema de Justicia a través de sus sentencias sobre amparo económico mediante la interpretación realizada en el último tiempo que priva de eficacia y efectividad al recurso de amparo económico a diferencia de la interpretación realizada en la década anterior por la misma Corte Suprema sobre la misma materia, que efectivamente cautelaba el derecho fundamental, en una interpretación 'favor homine' o 'favor personae', dotándolo de eficacia y efectividad, haciéndolo idóneo, conforme a su objeto y fin" (Nogueira, Humberto, cit. (n. 28), p. 17).

${ }^{34}$ Sobre la supletoriedad del Código Civil, véase: Vergara Blanco, Alejandro, Derecho administrativo y supuesta supletoriedad del Código Civil, en Revista de Derecho Administrativo, 3 (2009), pp. 45-68.

${ }^{35}$ Elementos gramatical, sistemático, histórico y teleológico, en SAvignY, C. F. von, Sistema de Derecho Romano actual (1840). En todo caso, sálvese el cuestionamiento que de esta teoría se formula en GuZmán Brito, Alejandro, Las reglas del 'Código Civil' de Chile sobre interpretación de las leyes (Santiago, LexisNexis, 2007), pp. 209-213, ya que, según el autor, no existe prueba documental fidedigna que permita afirmar que Andrés Bello, redactor del Código Civil chileno, haya seguido los criterios de Savigny.

${ }^{36}$ En el caso del Código Civil chileno, estas reglas se encuentran enunciadas en los artículos 19 a 24, que data de 1855. Para una revisión de la evolución histórica experimentada por este cuerpo legal, véanse los trabajos recogidos en GuZMÁN BRITO, 
testigos privilegiados del cambio de paradigma que ha experimentado el Derecho en el último medio siglo. Hijos de un contexto histórico monopolizado por el Estado de Derecho liberal-burgués del siglo XIX (en el cual la ley era la máxima expresión del Derecho, generada en un parlamento socialmente homogéneo, donde los conflictos jurídicos no llegaban a tener relevancia constitucional), pretenden un nivel de certeza en la interpretación de las normas que es incompatible con la positivación constitucional de contenidos materiales abiertos e indeterminados. Esta pretensión se justifica a partir de la desconfianza reinante hacia la arbitrariedad del juez, que intenta limitarse al vincular su labor a la ley, restándole espacio para decidir. En consecuencia, se postula la existencia de una interpretación correcta de la ley, aquella que tuvo en consideración el legislador al momento de redactar la norma ${ }^{37}$.

El propio enunciado gramatical de estos elementos de interpretación, da cuenta de un ejercicio que busca extraer de las entrañas de la norma su verdadero sentido o significado, ignorando tanto la posibilidad de conflicto entre diversas interpretaciones como de evolución en el contenido material de las normas. El recurso al tenor literal, al contexto histórico de generación de la norma, a su espíritu, al espíritu general de la legislación, en fin, a la equidad natural, dan cuenta de un sistema que busca encontrar aquella única interpretación posible de la norma, sin considerar que el Derecho es un fenómeno esencialmente cultural, resultado de las particulares combinaciones de las fuerzas políticas de determinado momento histórico. En suma, estas reglas no buscan la construcción de un significado en un proceso democrático y participativo, sino su alumbramiento. Es razonable que así sea, ya que pertenecen a una realidad histórica muy distinta a la presente; sin embargo, quedan en entredicho en la interpretación constitucional contemporánea, dada la vigencia normativa del principio democrático.

Las actuales notas distintivas de la Constitución contemporánea son incompatibles con esta definición epistemológica. La presencia de normas de principio, cuyo contenido material indeterminado es el reflejo de la pluralidad de la comunidad, abre la puerta a la necesidad de construir un significado del enunciado normativo, complementando estos criterios -más propios de la interpretación de normas con estructura de regla, siguiendo la clasificación de Alexy-con aquellos que incorporan la compleja estructura de las normas

Alejandro (editor), El Código Civil de Chile (1855-2005), Santiago, LexisNexis, 2005) 770 pp.

${ }^{37}$ Esta tendencia estuvo especialmente presente en los primeros intérpretes del Código Civil chileno que, al entender que el Código acogía un sistema literalista, redujeron el ejercicio de interpretación sólo a las situaciones de oscuridad de la ley. Cf. QuINTANA BRAvo, Fernando, Interpretación y argumentación jurídica (Santiago, Editorial Jurídica de Chile, 2006), pp. 217-220. 
constitucionales, condicionados por la positivación de principios materiales. En efecto, las normas con estructura de principio establecen, más que una conducta debida a partir de la verificación de supuesto de hecho, mandatos de optimización ${ }^{38}$, sin que sea posible deducir, de cada enunciado formal, un único y correcto contenido normativo.

Así, los criterios de interpretación de la ley son complementados por otros que atienden a las particularidades propias de la norma interpretada; avisar sobre la especificidad de la interpretación constitucional no significa denunciar los criterios tradicionales como inútiles. Por el contrario, el recurso a nuevos criterios implica reconocer tanto las bondades de los primeros como una primera herramienta de aproximación al texto de la norma, como sus limitaciones frente a una constitución que desborda las pretensiones de objetivación del ordenamiento jurídico decimonónico. En cambio, la constitución contemporánea asume como dato la pluralidad propia de la democracia, por lo que el carácter abierto e indeterminado de sus enunciados, tan lejano a los valores absolutos de antaño, a la vez que garantiza el pluralismo, puede generar un espacio de ambigüedad en el proceso de decisiones constitucionales. Sin perjuicio que la indeterminación no es un factor negativo en tanto garantiza la pluralidad del proceso democrático, el primer llamado a participar en el proceso de determinación de la Constitución es el legislador, en tanto órgano representativo de la voluntad popular, dado su carácter proporcional y colectivo.

\section{El tenor literal como criterio de interpretación.}

Si bien no hay distinción de incisos en la protección del artículo 19 No 21 C.Pol., ello no significa que el tenor de la ley es claro, ni que los criterios del Derecho civil sean los adecuados para interpretar la Constitución.

En relación a la claridad de la ley, si sólo aplicáramos el criterio gramatical, el rae. se tornaría en un recurso ambiguo respecto de la finalidad perseguida por el legislador. En efecto, de los documentos fundamentales en que aparece su ratio, es posible llegar a una conclusión distinta, por lo que es necesario acudir a otros principios de interpretación más allá de la letra de la ley, como son el lógico-histórico y el sistemático. Por lo demás, ya afirmar que el sentido de una norma es claro supone un acto de interpretación; por ello, no es posible recurrir a él para deslegitimar determinada interpretación, porque dicho recurso es, en sí mismo, una interpretación determinada.

${ }^{38}$ Cf. Alexy, Robert, Teoria de los derechos fundamentales (Madrid, Centro de Estudios Políticos y Constitucionales 2002), pp. 86 ss. 


\section{La historia fidedigna del establecimiento de la norma.}

Se ha señalado que la historia de la ley no establece claramente que el propósito original sería garantizar el orden público económico y prevenir frente a eventuales excesos del Estado empresario. La lectura que Hernández hace de la historia podría resultar más completa, si se consideraran fuentes documentales importantes que darían cuenta de ese propósito ${ }^{39}$.

De los antecedentes documentales que forman parte de la historia del establecimiento de la norma, es posible llegar a una conclusión diferente a la propuesta por Hernández. En efecto, tanto el "Mensaje" de la Ley $\mathrm{N}^{\circ}$ 18.971 como el "Informe técnico de los ministros del Interior, Economía y Hacienda" y el Informe № 6583/110/17 de la Primera Comisión Legislativa, dan cuenta de que el rae. se estableció con el fin de proteger a las personas, garantizando el respeto por el estatuto del Estado empresario ${ }^{40}$.

Ahora bien, recurrir a la historia no es suficiente para justificar un criterio interpretativo. Si así fuera, se caería en un originalismo hermenéutico que tiene el peligro de petrificar el Derecho o desactualizarlo. Sin embargo, sí es posible (y razonable) defender que la historia de la Ley $\mathrm{N}^{\circ} 18.971$ que establece el rae., tiene un propósito, a saber, que esta acción legal ha sido establecida para prevenir los excesos del Estado empresario y garantizar el respeto a su estatuto constitucional. Y en este punto discrepamos de lo que sostiene Hernández, para quien la historia de la ley no permite sostener la actual interpretación que está realizando la Corte Suprema

Ahora bien, ¿puede cambiar el actual criterio de interpretación de la Corte Suprema que, entre otros argumentos se funda en la historia fidedigna de la ley? Es evidente que puede cambiar, ya que la hermenéutica constitucional se asienta en criterios que carecen de la (pretendida) rigidez propia de la interpretación de la ley; en una sociedad democrática, en la que conviven diversas concepciones acerca de los mínimos protegidos por la Constitución, la apertura de la propia norma presiona sobre la flexibilidad de los criterios hermenéuticos, que podrán mutar en la medida que existan argumentos razonables.

\section{La interpretación de los derechos fundamentales.}

En concordancia con lo señalado precedentemente, el sistema de derechos fundamentales obedece a una lógica propia, a partir de la cual es posible identificar criterios hermenéuticos que no se derivan, necesariamente, del Derecho Civil. Se trata de un aspecto relevante en la evaluación de la nueva

\footnotetext{
${ }^{39} \mathrm{Al}$ respecto, véase HeRnández, Domingo, cit. (n. 15), pp. 447-449.

${ }^{40}$ Véase: Varas Alfonso, Paulino, Amparo económico, en Revista de Derecho Público, 49 (1991), pp. 47-56.
} 
jurisprudencia, considerando a libertad de empresa como un derecho fundamental.

Sin embargo, nos parece que la crítica esgrimida por Hernández y Nogueira, tiende a concebir el sistema de derechos fundamentales desde una perspectiva de clausura operativa (sistema cerrado); nos parece que los derechos se caracterizan por la relación dialéctica que existe entre ellos y por la apertura cognitiva del sistema. Ambos autores en este punto razonan como si el rae. operara en forma de silogismo: la libertad de empresa es un derecho fundamental; el rae. protege el artículo $19 \mathrm{~N}^{\circ} 21$; por consiguiente, el rae. sólo puede referirse a ambos incisos, por cuanto se asume que el inciso $2^{\circ}$ también contiene de un derecho fundamental. Esta interpretación, a juicio de los autores en comento, se aviene mejor al principio pro homine.

No obstante, un razonamiento cerrado de los derechos fundamentales no permite observar la tensión que puede generar el ejercicio de este derecho frente a otros; ni que la libertad de empresa se encuentra debidamente protegida por otras vías jurisdiccionales. Nos parece que desde la perspectiva de un sistema complejo de derechos fundamentales como el actual, la nueva tendencia jurisprudencial se aviene mejor con un modelo de interrelación razonable entre los derechos. La libertad de empresa no quedará en la indefensión con la nueva interpretación, ya que el ordenamiento jurídico contempla vías más especializadas de tutela, comenzando por el propio recurso de protección.

Hasta el giro hermenéutico de la Corte Suprema, la jurisprudencia hizo del rae. una suerte de "súper protección", reflejo de una lectura neoliberal del modelo económico social que se ha impuesto en $\mathrm{Chile}^{41}$. Al parecer, para esa

${ }^{41}$ Sobre el carácter neoliberal del modelo político que se ha impuesto en Chile, entre muchos, véanse: Fontaine Aldunate, Arturo, Más allá del Leviatán, en Estudios Públicos, 1 (1980), p. 5; Fontaine Aldunate, Arturo, Los economistas y el presidente Pinochet (Santiago, Zig-Zag, 1988), pp. 21-38; Foxley, Alejandro, Experimentos neoliberales en América Latina (Colección Estudios Cieplan, Numero Especial, Santiago, 1982), p. 38; Vergara, Pilar, cit. (n. 4), p. 56; LeChner, Norbert, El proyecto neoconservador y la democracia, en Obras escogidas de Norbert Lechner (Santiago, LOM, 2007), II, p. 138; LeCHNER, Norbert, El debate sobre Estado y mercado, en Estudios Públicos, 47 (1992), pp. 235-247; Salazar, Gabriel - Pinto, Julio, Historia contemporánea de Chile (Santiago, LOM, 1999), I, p. 175; Garretón, Manuel Antonio, Modelo y proyecto politico del régimen militar, en Garretón, Manuel Antonio y otros, Chile 1973-198? (Santiago, Flacso, 1983), p. 20; SAntos Herceg, José, Anomalias del modelo neoliberal en Chile. La Universidad chilena hoy: el espejismo de su progreso, en Estudios Avanzados, 5 (2006) 7, pp. 1-12. disponible en: http://web. usach.cl/revistaidea/html/revista\%207/pdf/santos.pdf [fecha de visita 16 de mayo de 2012]; ZúÑIga Urbina, Francisco, Jurisprudencia del Tribunal Constitucional acerca de derechos económicos, sociales y culturales, en Revista de Derecho del Consejo de Defensa del Estado, 20 (2008), p. 88. 
corriente interpretativa, no eran suficientes las herramientas que existen para proteger la libre empresa, sino que es necesario reforzarla y nada mejor que ampliar la original intención del legislador. Y eso llevó a una sobreprotección de la libertad de empresa, lo que no se cohonesta con un sistema democrático contemporáneo que pone el acento en la estructura social del sistema político. De ahí el problema que presenta la propuesta de interpretación en código de sistema cerrado, como es la de Hernández y Nogueira, que no permite ni favorece la apertura cognitiva del sistema de derechos fundamentales ${ }^{42}$.

Además, y dada la emergencia fáctica de este "mega recurso", habría que preguntarse, como lo hace Ruiz-Tagle, “por qué muchos de los recursos de amparo económico son interpuestos por asociaciones gremiales o agrupaciones que a veces parecen defender una estructura de mercado determinada que le es favorable para seguir desarrollado sus negocios de manera tradicional" 43 . No sería aventurado afirmar que la praxis que generó una interpretación amplia del rae., vigente hasta 2009, no favoreció ni la libre competencia ni la prohibición de la discriminación arbitraria, que son los pilares en los cuales descansa un mercado ordenado ${ }^{44}$.

5. La estructura de las normas constitucionales. Diferencias entre los incisos $1^{\circ}$ y $2^{\circ}$ del artículo $19 N^{\circ} 21$ C.Pol.

$\mathrm{Al}$ analizar el artículo 19 No 21 C.Pol., es posible concluir que sólo el inciso $1^{\circ}$ formula o protege un derecho fundamental, el derecho a la libertad económica, mientras que el inciso $2^{\circ}$ sólo contempla las reglas formales a través de las cuales se regulará la actividad empresarial del Estado. Es decir, una norma para el derecho fundamental y otra para el estatuto del Estado empresario. Ahora bien, ¿qué establece realmente el inciso $2^{\circ}$ del artículo 19 No 21 de la Carta? Se ha argumentado que a partir de dicha norma se estructura el orden público económico que rige en nuestro país, condicionando la intervención estatal en la economía y las actividades económicas que el Estado pueda desarrollar ${ }^{45}$.

Sin entrar en el detalle de dicha institución, objetivo que escapa a las pretensiones del presente trabajo, sólo nos interesa poner el acento en un aspecto: el contenido que se le atribuye al orden público económico en general, y al estatuto del Estado empresario en particular, no se desprende pura y simplemente del texto de la Constitución. Es decir, el contenido material

\footnotetext{
${ }^{42}$ Ya en 2001, criticaba el cambio de paradigma interpretativo de la Corte Suprema (véase ZúÑiga Urbina, Francisco, cit. [n.41], pp. 307-309).

${ }^{43}$ Ruiz-Tagle, Pablo, Principios constitucionales del Estado empresario, en Revista de Derecho Público, 62 (2000), p. 64.

${ }^{44}$ Véase: Ruiz-Tagle, Pablo, cit. (n. 43), p. 63.

${ }^{45}$ Principalmente, Fermandois, Arturo, cit. (n. 3), pp. 72-74.
} 
de este concepto no es autoevidente. Por el contrario, éste se ha construido hermenéuticamente por la jurisprudencia y, especialmente, por la doctrina. Ha sido la doctrina la que, a partir de la interpretación del texto vigente, ha afirmado que la Constitución consagra determinada institución o protege determinado modelo.

Ahora bien, si la actual conformación del Estado empresario obedece más a la construcción interpretativa que cierto sector de la doctrina hace de ciertas normas constitucionales, que al contenido normativo del artículo $19 \mathrm{~N}^{\circ} 21$ C.Pol., es posible cuestionar la función de la interpretación constitucional en la configuración del ordenamiento jurídico. En concreto, el contenido propiamente constitucional de la garantía es estrictamente formal, por cuanto le entrega al legislador la competencia para autorizar la actividad empresarial del Estado y determinar las reglas que la regularán (inciso $2^{\circ}$ ) y, por consiguiente, la garantía para el ejercicio del derecho a la libertad económica.

En efecto, doctrina y jurisprudencia han cumplido una función clave en la determinación del contenido material del estatuto del Estado empresario. La interpretación combinada de determinadas normas constitucionales arroja como resultado un estatuto basado en la subsidiariedad, interpretada en su esfera negativa, la propiedad privada y la libertad económica. Sin embargo, se decide no construir el concepto considerando otros principios también presentes en la Constitución, como el principio de solidaridad o la igualdad de oportunidades. Se trata, en definitiva, de un contenido posible del estatuto del Estado empresario, pero no de un contenido necesario; es decir, una selección y combinación diferente de los principios constitucionales podría arrojar, legítimamente, una configuración diferente del estatuto en comento. $\mathrm{Y}$ esto es aplicable a cualquier norma constitucional con estructura de principio, dada la indeterminación de su contenido material y su necesaria concreción a partir de la interpretación.

Ahora bien, el que la Constitución no posea un contenido fijo para las normas constitucionales de principio, lo que también se verifica en el estatuto del Estado empresario, forma parte de la garantía de libertad política que se identifica en la indeterminación de estas normas ${ }^{46}$. Es decir, su concreción posterior por el legislador supone proteger la autodeterminación normativa del pueblo soberano, en aquellas materias que no pueden quedar predeterminadas por la Constitución. En ese contexto se entiende, por ejemplo, la reserva de ley como garantía al ejercicio de los derechos fundamentales ( $\left.19 \mathrm{~N}^{\circ} 26\right)$

${ }^{46}$ Véase Hesse, Konrad, Concepto y cualidad de la Constitución, en Hesse, Escritos de Derecho Constitucional (Madrid, Centro de Estudios Constitucionales, 1983), pp. 19 ss. 
y el propio principio de legalidad como contenido de ciertas garantías (19 $\left.\mathrm{N}^{\circ} 3, \mathrm{~N}^{\circ} 24\right)$, así como el propio contenido formal del estatuto del Estado empresario, contemplado en el artículo $19 \mathrm{~N}^{\circ} 21$ inciso $2^{\circ} \mathrm{C}$.Pol.

Lo anterior respalda la actual interpretación que la Corte Suprema hace de la aplicación de la Ley $\mathrm{N}^{\circ} 18.971$ : dado que el inciso $1^{\circ}$ del artículo $19 \mathrm{~N}^{\circ}$ 21 C.Pol. protege un derecho fundamental, que reviste un interés particular en su ejercicio, éste se protege mediante una acción de tutela especial, que busca el restablecimiento del imperio del Derecho; es decir, el cese de la vulneración en el legítimo ejercicio del derecho fundamental. En cambio, el inciso $2^{\circ}$ establece las reglas formales a partir de las cuales se configura el estatuto del Estado empresario; aquí hay un interés público comprometido, lo que explica las características de la acción de amparo económico, su plazo, su carácter de acción pública e, incluso, el trámite de consulta obligada. Ni el inciso $2^{\circ}$ en comento ni el rae. protegen explícitamente un derecho fundamental, sino la garantía para el respeto de un estatuto de orden público; he ahí su tutela especial y que se distingue de la acción de protección del artículo 20 de la Carta. Ello añade una justificación, a nuestro juicio, a la nueva línea argumentativa de la Corte, en el sentido de garantizar el respeto del estatuto del Estado empresario a través del rae. y la garantía del legítimo ejercicio del derecho fundamental a través de la acción de protección.

\section{Conclusiones}

1. La "constitución económica" chilena no es neutra, sino que abraza un determinado modelo económico. Con todo, la economía de mercado no puede ser comprendida en una única versión, sino que es un sistema abierto, que admite diversas interpretaciones y que, desde la perspectiva política supone un techo ideológico con apertura, que no obsta a la participación del Estado como agente económico.

2. La libre iniciativa económica, consagrada en el inciso 1 del artículo 19 $\mathrm{N}^{\circ} 21$ C.Pol. es un derecho fundamental, que no tiene privilegios en el marco del complejo sistema de derechos fundamentales. Por lo mismo, valoramos positivamente la nueva interpretación que la Corte Suprema está realizando en relación a su ámbito de protección.

3. Los elementos de interpretación propios del Derecho privado, si bien pueden ser útiles en Derecho constitucional, son insuficientes. La razón radica en que la apertura y estructura normativa de las normas constitucionales favorecen la existencia de un sistema interpretativo abierto y flexible. La norma constitucional es estructuralmente distinta de la norma legal, siendo su mayor diferencia el mayor grado de generalidad y abstracción que la caracteriza y que resulta no sólo del enunciado normativo, sino también del 
hecho que forma parte de un sistema que es amplio y configura al legislativo como un órgano que actúa con libertad dentro de los límites establecidos por la Constitución.

4. Por lo mismo, la nueva interpretación sobre el rae. que está realizando la Corte Suprema, junto con limitar los privilegios de tutela que se habían otorgado a la libre iniciativa económica, restablece la importancia del recurso de protección en este derecho, como también las vías complementarias de defensa del sistema de mercado y la libre competencia.

5. Finalmente, la estructura normativa de los incisos $1^{\circ}$ y $2^{\circ}$ del artículo 19 № 21.Pol. constituyen elementos de discernimiento que permiten respaldar el giro hermenéutico que ha dado la Corte Suprema. En efecto, atendiendo a que sólo es posible identificar la formulación normativa de un derecho fundamental en el inciso $1^{\circ}$ de dicho artículo, parece razonable que el rae. se reserve a la protección de aquel interés público que trasciende al interés particular propio del derecho fundamental. Así, donde existe un interés púbico, concretamente en la protección del estatuto del Estado empresario del inciso $2^{\circ}$, parece razonable que se establezca una garantía jurisdiccional diferenciada, que se condiga con dicho interés; a su vez, allí donde existe un interés particular, en el ejercicio del derecho fundamental a la libertad de emprendimiento, se proteja con una acción cautelar especial que busca el pronto restablecimiento del imperio del Derecho. En suma, la diferente estructura normativa de ambos incisos explica que existan mecanismos diferenciados de protección, cuyas particularidades obedecen, precisamente, a la protección de diferentes intereses en el artículo 19 No 21 C.Pol.

\section{BIBLIOGRAFÍA}

Alexy, Robert, Teoría de los derechos fundamentales (Madrid, Centro de Estudios Políticos y Constitucionales, 2002), 607 pp.

Avilés Hernández, Víctor, Orden público económico: noción critica, en Revista de Derecho Público, 63 (2001).

Bassa Mercado, Jaime, Neutralidad politica y enseñanza del Derecho constitucional en Chile, en Henrí uez, Miriam (coordinadora), Perspectiva del Derecho constitucional desde el mirador del Bicentenario (Santiago, Asociación Chilena de Derecho Constitucional, 2011).

Bertelsen Repetto, Raúl, El Estado empresario en la Constitución de 1980, en Revista chilena de Derecho, 14 (1987) 1.

Cuevas Farren, Gustavo, Protección Constitucional de la libertad económica. Notas y reflexiones, en Letras Juridicas, 2 (Universidad de Guadalajara, 2006).

Dougnac Rodríguez, Fernando, La garantía constitucional del $N^{\circ} 21$ del artículo 19 de la Constitución en relación con las demás que configuran el 'orden público económico', en Gaceta Jurídica, 68 (1986). 
Estévez Valencia, Jaime, Visión sobre la Constitución Económica, en Revista de Derecho Público, 62 (2000).

FARÍAS KANACRI, Alejandro, El derecho a desarrollar actividades económicas y su regulación, en Persona y Sociedad, 4 (2000) 3.

Fermandois, Arturo, Derecho constitucional económico (2a edición, Ediciones Universidad Católica de Chile, Santiago, 2006), I.

Ferrada Bórquez, Juan Carlos, La Constitución de 1980. Algunas reflexiones criticas, en Revista de Derecho Universidad Austral de Valdivia, 11 (2000).

Fontaine Aldunate, Arturo, Los economistas y el Presidente Pinochet (Zig-Zag, Santiago, 1988).

Fontaine Aldunate, Arturo, Más allá del Leviatán, en Estudios Públicos, 1 (1980).

Foxley, Alejandro, Experimentos neoliberales en América Latina (Colección Estudios Cieplan, Número Especial, Santiago, 1982).

GARRETón, Manuel Antonio, Modelo y proyecto político del régimen militar, en GARRETón, Manuel Antonio y otros, Chile 1973-198? (Santiago, Flacso, 1983).

Guerrero Becar, José Luis, La libertad para desarrollar actividades económicas del artículo $19 N^{\circ} 21$ y la Constitución Económica, en Persona y Sociedad, 4 (2000) 3.

Guzmán SuÁrez, Lionel, Paralelo entre el recurso de protección y el recurso de amparo económico, en Gaceta Jurídica, 182 (1999).

Hernández Emparanza, Domingo, El recurso de amparo económico: una tendencia jurisprudencial peligrosamente reduccionista, en Estudios Constitucionales, 8 (2010) 1.

Hesse, Konrad, Concepto y cualidad de la Constitución, en Hesse, Escritos de Derecho Constitucional (Madrid, Centro de Estudios Constitucionales, 1983).

LANDERretche, Oscar, Notas sobre el rol del Estado en la Economía, en La Revista de Derecho, 4 (Universidad Central, 2003).

Larroulet Vignau, Cristián, Visión Económica de la Constitución de 1980, en Revista de Derecho Público, 62 (Universidad de Chile, 2000).

LeChner, Norbert, El debate sobre Estado y mercado, en Estudios Públicos, 47 (1992).

LECHNER, Norbert, El proyecto neoconservador y la democracia, en Obras escogidas de Norbert Lechner (Santiago, LOM, 2007), II.

Masbernat Muñoz, Patricio - Hurtado Contreras, José Tomás, Crítica al concepto de orden público económico, en Revista de Derecho Público, 66 (Universidad de Chile, 2004).

Navarro Beltrán, Enrique, El Estado empresario a la luz de la Constitución de 1980, en Revista de Derecho Público, 62 (Universidad de Chile, 2000).

Navarro Beltrán, Enrique, El recurso de amparo económico y su práctica jurisprudencial, en Estudios Constitucionales, a 5 (2007) 2.

Nogueira Alcalá, Humberto, Análisis critico sobre línea jurisprudencial de la Sala Constitucional de la Excma. Corte Suprema de Justicia sobre el recurso de amparo económico, en Gaceta Jurídica, 360 (2010).

Nogueira Alcalá, Humberto, Análisis crítico sobre línea jurisprudencial de la Sala Constitucional de la Excma. Corte Suprema de Justicia sobre el recurso de amparo económico, en Ius et Praxis, 16 (Universidad de Talca, 2010) 2.

QuiNTANA BRAvo, Fernando, Interpretación y argumentación jurídica (Santiago, Editorial Jurídica de Chile, 2006), 338 pp. 
Ruiz-Tagle, Pablo, Principios constitucionales del Estado empresario, en Revista de Derecho Público, , 62 (Universidad de Chile, 2000).

Salazar, Gabriel - Pinto, Julio, Historia contemporánea de Chile (Santiago, LOM, 1999), I.

Santos Herceg, José, Anomalias del modelo neoliberal en Chile. La Universidad chilena hoy: el espejismo de su progreso, en Estudios Avanzados, 5 (2006) 7.

Soto Kloss, Eduardo, La actividad económica en la Constitución Politica de la República de Chile (La primacía de la persona humana), en Ius Publicum, 2 (Universidad Santo Tomás, 1999).

Varas Alfonso, Paulino, Amparo económico, en Revista de Derecho Público, 49 (Universidad de Chile, 1991).

Vergara Blanco, Alejandro, Derecho Administrativo y supuesta supletoriedad del Código Civil, en Revista de Derecho Administrativo, 3 (2009).

Vergara, Pilar, Auge y caida del neoliberalismo en Chile (Santiago, Flacso, 1985).

ZúNiga Urbina, Francisco, 'Constitución económica' y Estado empresario, en Revista de Derecho Público, 63 (Universidad de Chile, 2001).

ZúNiga Urbina, Francisco, El recurso de amparo económico: doctrina jurisprudencial, en La Revista de Derecho, 2 (Universidad Central de Chile, 2001).

Zúñiga Urbina, Francisco, Jurisprudencia del Tribunal Constitucional acerca de derechos económicos, sociales y culturales, en Revista de Derecho, Consejo de Defensa del Estado, 20 (2008).

ZúÑ́lga Urbina, Francisco, Vieja-Nueva Constitución, en Estudios Constitucionales, $1(2007) 5$. 
